\title{
Business Strategies for Transitions Towards Sustainable Systems
}

\author{
Derk Loorbach, ${ }^{1 *}$ Janneke C. van Bakel, ${ }^{2}$ Gail Whiteman ${ }^{3}$ and Jan Rotmans ${ }^{1}$ \\ ${ }^{1}$ Dutch Research Institute for Transitions (DRIFT), Faculty of Social Sciences, \\ Erasmus University Rotterdam, Rotterdam, The Netherlands \\ ${ }^{2}$ Provincie Utrecht, Utrecht, The Netherlands \\ ${ }^{3}$ Rotterdam School of Management, Erasmus University, Rotterdam, The Netherlands
}

\begin{abstract}
This paper develops a strategic perspective for business to contribute to the innovation of societal systems. Sustainability issues at the level of societal sectors cannot be addressed by single organizations but need to be thought of as systemic challenges in which business, government and civil society each play different roles. Sustainability involves structural changes over longer periods of time, and requires co-evolutionary changes in technology, economy, culture and organizational forms. We propose that the transition management framework offers a fruitful way to analyze such co-evolutionary processes of social transformation and subsequently develop strategies to influence and accelerate such processes. We present the case of two firms working in this new context of transition management in The Netherlands. From these cases we conceptualize a more general approach for business to redefine and reframe the societal context in which it is operating and develop novel business strategies. Copyright (C) 2009 John Wiley \& Sons, Ltd and ERP Environment.
\end{abstract}

Received 18 February 2008; revised 16 November 2008; accepted 24 November 2008

Keywords: sustainable development; business development; transition management; strategy

\section{Introduction}

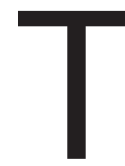

HE PROBLEMS FACING OUR SOCIETY IN TERMS OF NON-SUSTAINABILITY ARE INCREASINGLY COMPLEX AND OFTEN persistent in nature. Persistent environmental issues such as climate change or non-sustainable mobility are hard to resolve because they tend to be deeply embedded in societal structures and institutions (Rotmans et al., 200I). They have multiple causes and consequences and their reach extends beyond a wide range of societal domains, actors and scale levels. Such issues are unlikely to be solved by contemporary government policies or individual firms in isolation. Instead, Rotmans et al. (2000) argue that they require a structural change of the system in terms of technology, economy, culture, ecology and institutions and organization. During the last seven years, Dutch researchers have developed an approach to influence and guide transitions towards sustainability (Rotmans et al., 2000; Loorbach, 2007). In 200I, the Dutch government adopted 'transition management' as the official government policy to deal with persistent problems of non-sustainability (VROM,

* Correspondence to: Derk Loorbach, Dutch Research Institute for Transitions (DRIFT), Faculty of Social Sciences, Erasmus University Rotterdam, P.O. Box 1738, 3000 DR Rotterdam, The Netherlands. E-mail: loorbach@fsw.eur.nl 
200I). This paper presents a strategic perspective for business to contribute to the transition of societal systems based upon two case examples of transition management from The Netherlands.

Empirical research that examines the strategic practices of business to structurally change the way societal systems operate in order to address persistent environmental and social problems is not well developed (Porter, 2006; Shrivastava, I995; Starik and Marcus, 2000). To date, the academic literature has largely focused on business performance and sustainability at the firm or industry level (Bansal and Gao, 2006; Jermier et al, 2006, King and Lenox, 2000). However 'firms alone cannot become sustainable in an economic, environmental and social sense as they merely contribute to more sustainable patterns of production and consumption within society' (Roome, 2006, p. 137). The complexity and persistent nature of sustainability issues pose new challenges on business, which requires new conceptual models for researching the relation between firms and the natural environment.

Research on business and the natural environment has grown dramatically over the years (Bansal and Gao, 2006). The majority of studies in this field attempt to measure or explain environmental performances of organizations, e.g. in terms of waste production or resource use, adoption of ISO I400I or how regulation influences performance (Bansal and Gao, 2006; Jermier et al., 2006). However, persistent sustainability issues - such as climate change or mobility problems - require more radical and structural changes within and between organizations (Rotmans, 2005), for which reduction of environmental impact by individual firms does not suffice. It is increasingly argued that eco-efficiency strategies (Korhonen and Seager, 2008) and incremental change (Könnölla and Unruh, 2008) in business support current lock-in and in the end lead to sub-optimal innovation trajectories.

In contrast, coevolutionary logic assumes that the firm has a symbiotic, coevolving relationship with society and ecosystems (Korhonen and Seager, 2008; Porter, 2006). Porter also proposes that coevolutionary mechanisms provide business researchers and managers with a systems perspective that links firm level activities to the societal level effects in an iterative process. However, the coevolution between business activities and changing societal systems, and the opportunities and challenges this creates for business in strategically addressing sustainability issues, has scarcely been researched (Korhonen and Seager, 2008). Seager (2008, p. 448) argues that 'application of sustainability knowledge in decision making, management, policy and design can be recognized as a necessity, but remains in mere nascent stages of development and may even depend upon further progress in other fields to become fully realized'.

This is an important gap in the literature that our paper hopes to address. We present two empirical examples of a systemic approach to dealing with sustainability problems from The Netherlands. Within the Dutch context, these cases are part of a larger government initiative to experiment with transition management - a combined conceptual and applied approach for researching and implementing structural changes at the societal level and concretely influencing transitions towards sustainability (Rotmans et al., 2000). We examine the strategic role of the firm within such transitions.

The paper includes four sections. The first section reviews the literature on individual and collaborative sustainability approaches of firms and introduces transition concepts. The second section illustrates how two companies that operate in a context where transition management is applied take a different approach to sustainability issues. In the third section we discuss our findings and present a framework for conceptualizing business strategies for transitions towards sustainable systems. The paper concludes by indicating implications for further research and policy recommendations.

\section{Business, the Environment and Transitions}

In a broad sense the literature on sustainability aims to provide better understanding of the relationship between business and the environment. Looking more closely, existing literature can be characterized as firm or industry level focused (Bansal and Gao, 2006; Jermier et al., 2006). Although Starik and Rands (I995) provided a framework to study the relationship between the organization and other levels of analysis (political-economic, socialcultural, ecological and individual), interactions between different levels are hardly investigated (Bansal and Gao, 2006; Korhonen and Seager, 2008). While corporate environmentalism has developed from reactive responses in 


\section{Business Strategies for Transitions Towards Sustainable Systems}

the early years to more proactive business strategies (see, e.g., Carroll, I999; Hoffman, I997; Jermier et al., 2006), firms still focus more on reducing unsustainable firm-level behavior than on increasing the sustainability of the system via radical change across actors and levels (Ehrenfeld, 2005; Korhonen and Seager, 2008).

More recently, researchers have proposed that we should focus more on interdependencies between business and society and take collaborative approaches to create system change (Baas, 2008; Boons and Roome, 2005; Porter, 2006; Svendsen and Laberge, 2005). From the assumption that sustainability issues are too complex and interconnected to be solved by individual firms, several researchers have developed network and systems approaches to sustainability issues (Boons and Roome, 2005; Svendsen and Laberge, 2005; Westley and Vredenburg, I997; Wheeler et al., 2005). Most of these studies accordingly use the network as the unit of analysis instead of the individual firm. Sustainability activities of firms are conceptualized as corporate engagement in collaborative efforts with multiple stakeholders to a address social issues (Svendsen and Laberge, 2006) since stakeholder networks can help firms tap into co-creative power: the capacity of the network to self-organize, find novel solutions and adapt to environmental changes. Firms, in collaboration with other stakeholders, create learning-action networks (Clarke and Roome, I999; Westley, I995) and develop new capabilities within clusters of innovation with respect to sustainability, at the level of a product, sustainable technology, industry sector or geographic area (Boons and Roome, 2005).

Collective learning is essential for system innovation as it helps to develop knowledge about root causes, linkages and patterns, to construct shared meanings and to clarify common ground and differences in perspectives, interest and needs (Svendsen and Laberge, 2005). To some extent, especially in the context of unstructured and complex societal issues, we can think of this as 'unlearning': the questioning and shedding of institutionalized routines that provide a barrier to collaborative approaches to sustainable development (Baas, 2008). Firms need to have an appropriate culture for this, with collaborative capabilities and values such as being open and responsive to multiple perspectives, building networks and developing mutual understanding (Boons and Roome, 2005; Clarke and Roome, I999; Wheeler et al., 2003). Other conditions for multi-stakeholder processes include defining the goals of the network, clarifying roles and responsibilities, agreeing on shared rules and norms and collective learning (Gray, I989). Through interaction, people build trust and commitment (Ring and Van de Ven, I994; Taanman et al, submitted), which is essential for effective collaborative action.

Although this literature gives insight in collaboration processes and required capabilities of firms, it hardly takes into account the larger context in which this takes place. By context we mean the dynamics of the larger societal system: the actors involved in a certain domain, (power) relations between them and dominant practices and mindsets. As a result, the complexity and persistent nature of many sustainability issues seems to be largely underestimated. Through research on coevolutionary mechanisms (Lewin and Volberda, I999), which draws from evolutionary and complexity theory, scholars can create better understanding of co-evolution between firms and societal and ecological systems and between people's value systems and technical solutions (Korhonen and Seager, 2008; Porter, 2006). While appealing at the conceptual level, there are only a few empirical studies examining a co-evolutionary approach to sustainability (e.g. Baas, 2008).

The co-evolutionary perspective is also a central element in the research on societal transitions. Rotmans et al. (2000) argue that, from a sustainable development perspective, transitions are necessary to deal with persistent problems and unsustainable social systems such as mobility, agriculture, energy, education and health-care. A transition is defined as a long term process - it may take one or more generations - of non-linear social change leading to new constellations of actors, structures and practices, which determine the functioning of the system (De Haan, 2007). A transition emerges out of co-evolutionary processes in which institutional, technological, behavioral, ecological, economic and other processes intertwine and reinforce each other. Transitions consist of a number of system innovations: 'organization-transcending innovations that drastically alter the relationships between companies, organizations and individuals involved in the system', such as an economic sector, societal domain or region (Rotmans, 2005, p. II).

Two main concepts are used to describe and analyze transitions. The multi-level concept describes the dynamics of a transition as the interactions between different scale levels (Geels and Kemp, 2000; Rotmans et al, 2000): the meso-level at which a regime of dominant structures, culture and practices operates, a micro-level of niches, innovations and alternatives to the regime and a macro-level of societal trends and developments. The multi-stage concept is used to describe the different phases of transition: predevelopment (tension is building on a vested 
regime but not much seems to happen), take-off (multiple developments interlock and cause a sudden chaotic period), acceleration (change is quickly materializing and leading to radically new structures) and stabilization (the process of change slows down and results in a new but fundamentally different dynamic equilibrium). The multilevel and multi-phase concepts combined enable an analysis of causes and drivers for transitions and an assessment of the state of a societal system. Once patterns and mechanisms in a system are identified, opportunities for influencing them arise.

To direct transitions towards sustainability, new modes of governance are needed that take into account the long time-horizon, the uncertainties and complexities and the multitude of actors and interests involved. Many scholars over the past 15 years have both pointed to the spontaneous emergence of novel government-society interactions (Hooghe and Marks, 200I; Kooiman, I993; Mayntz, I993) and emphasized the need for more structured and effective governance models (Klijn and Koppenjan, 2000; March and Olson, I995; Milward and Provan, 2000; Rhodes, I996). However, only recently focus in governance studies has shifted from a purely process oriented approach to more explicitly combining network approaches with system thinking (Westley, I995) and the need for sustainability transitions. For instance, Loorbach (2007) points to the importance of bringing together stakeholders to understand root causes of persistent complex problems. He argues, unlike much of the previous literature on collaboration, to compose small groups of frontrunners that are able to reframe problems into attractive sustainability visions, instead of representatives of all organizations involved in an issue. Complexity governance means creating institutional, mental and financial space for innovation, emergence and (self-)organization: in other words, space for building up alternative regimes.

Transition management (Rotmans et al., 200I; Loorbach, 2007) is a governance approach that is developed in iteration between theoretical insight in transition dynamics (including structures and actors) and experimental implementation of transition management instruments and ideas. It is, in terms of thinking, closely related to complex system thinking and resilience theory (Holling, I9 86), which is a quickly emerging paradigm in a number of disciplines, including business studies (Korhonen and Seager, 2008). Transition management is focused upon the management of specific patterns of structural system change from one equilibrium (or regime) to another as it is applied to social systems. Transition management is a prescriptive governance approach including a framework for experimental implementation. We shall argue, through two cases, that transition management offers a practical framework for frontrunner (business) actors to strategically deal with system change in society.

\section{Cases: Firms' Strategies in Transitions in The Netherlands}

\section{Methodology}

Our research was a grounded theory study (Strauss and Corbin, I990) of two Dutch firms taking advantage of the emerging new governance context in The Netherlands related to sustainable development. The two cases describe the firms' strategies, activities and choices at different levels and the interaction with their environment. The study on ESHA Group draws on participatory observation, document analysis and a number of interviews with the CEO in the period between January 2007 and September 2008. The study on Pon Holdings is based on interviews with two directors of business development and the secretary of the platform for sustainable mobility, presentation material and document analysis.

Both cases illustrate how the transition management approach can be used to rethink the context within which firms operate and develop new ideas and strategies to proactively deal with this context. The cases provide us with empirical data on how firms deal with persistent sustainability issues strategically in a changing environment.

\section{Context: the Transition Management Approach}

In The Netherlands the energy transition process is the largest application of transition management (TM) principles, which forms the context of our empirical cases. This process started in 200I, based on a report in which the basic approach of transition management was presented (Rotmans et al., 200I). Since then, transition management has rapidly developed in The Netherlands, stimulated by a national research program on transitions and an 


\section{Business Strategies for Transitions Towards Sustainable Systems}

increasing number of areas in which transition management is implemented. Examples are waste management, mobility, built environment, health care and on a regional scale (see Loorbach, 2007). Moreover, two large scale processes have started in Flanders, Belgium, since 2003. In this paper we try to further develop the transition management approach, by building on insights into its implementation over the past years and recent theoretical development.

TM starts with the concept that society is a patchwork of complex adaptive systems. 'The basic steering philosophy underlying TM is that of anticipation and adaptation, starting from a macro-vision on sustainability, building upon (micro) initiatives, meanwhile influencing the meso-regime' (Loorbach, 2007, p. 82). In this approach, complexity and uncertainty are seen not as problems, but as driving forces of societal change and as levers for governance, opposing recent management approaches that emphasize the uncertainty, unpredictability and unmanageability in complex societal contexts (Stacey et al., 2000). Transition management takes a process approach that aims to change the dominant culture, structures and practices of unsustainable systems by linking innovations at the micro level to macro level changes in mindsets. This requires different roles and practices from individual actors involved, such as companies, scientific institutes, governmental organizations or NGOs. From a governance point of view, three different types of activity and new roles were distinguished and conceptualized as strategic, tactical and operational transition management (Loorbach, 2007).

Strategic transition management activities seek to develop a shared understanding of reality (structure the complex problem(s) at hand and find root causes of the problem by sharing and converging diverse problem perceptions) and a sustainability vision amongst a relatively small innovation network of forerunners (a transition arena). Joint insights and long-term ambitions and goals are formulated that act as cognitive frames for individual action. The strategic level thus requires strategic thinkers that are open to change and reflection.

Tactical transition management aims to gain societal support and attention for sustainability objectives and intermediary goals at the level of subsystems by developing support networks and coalitions around transition pathways. The main challenge here is to identify and overcome structural barriers - such as regulations, market conditions, technologies and consumer routines - to development in the desired direction.

Operational transition management primarily aims to experiment with, develop and learn about the potential of various innovations - such as new technologies, practices, products or organization - and their contribution to the overall transition. This means developing portfolios of experiments and innovations (technological, institutional, behavioral, organizational etc.) that have potential to materialize the strategic vision and develop into new, more sustainable practices and structures. Transition experiments inform actors about specific barriers for implementation in different environments.

Based on the first outlines of this TM approach, the Ministry of Economic Affairs has developed an experimental and innovative process in the area of sustainable energy in which all sorts of actors are involved at different levels around a shared transition vision and agenda, named the energy transition (EZ, 2004). They developed a number of transition arenas, small networks of selected frontrunners with different backgrounds, which go through a process of co-developing a vision, transition agenda and experiments. The transition arenas around themes such as green resources, green electricity and new gas laid the foundations for the development of communities of innovative actors that co-produce, implement and evaluate strategies and experiments. A large number of experiments - technological as well as organizational - have been funded, and increasing political and public attention is drawn to the energy transition process. In this new context of governance in which self-organization and experimentation is stimulated and facilitated, new initiatives from individual firms have room to mature and become adapted on a wider scale. In practice, these experiments have demonstrated that an essential condition for transition management is to have common insight into how the system works (Loorbach, 2007). That is, what are dominant practices, technologies and ways of thinking, what (power) relations can be recognized, what types of regulation or other incentive influence behavior of actors?

While transition management basically is a new governance approach at a societal level, our empirical data show that the approach can also support individual firms in concurrently developing their own business and contributing to transitions towards sustainable systems. We illustrate this by two cases. 


\section{Loorbach et al.}

\section{ESHA Group Transitioning Roofs}

An example of how a firm might use transition management to create new business opportunities, to improve its image and to contribute to societal innovation and sustainability is the ESHA Group, ${ }^{\mathrm{I}}$ part of the Icopal Group, and producer and manufacturer of bituminous products. Bitumen is a by-product of the oil industry and is used for roofs (the black tarlike roof coating). Traditionally, bitumen roofs have no other function than as a cover for buildings, but since 2006 ESHA has begun to take advantage of a technological innovation that allows roofs to also provide important urban ecological functions. ESHA has actively developed innovative and sustainable solutions for roofs such as green roofs that can buffer water or contribute to cleaner air. In 2007, the CEO of ESHA started up a new strategy to broaden the activities of ESHA and the context in which their activities take place.

In late 2006, ESHA came up with the idea of roof transition. At a strategic level, technology developers, marketers, policy experts and a toxicologist developed a new paradigm and vision related to roofs. No longer should roofs only be regarded as roofs: the current 350 million square meters of traditional roofs should be transformed into roofs that contribute to sustainability in society. A research commissioned by ESHA and executed by the Dutch institute TNO calculated that the reduction in $\mathrm{CO}_{2}$ emission of replacing one square meter of traditional roof by a sustainable solution is equal to the $\mathrm{CO}_{2}$ emissions of driving one kilometer by car. ESHA adopted an innovative systems approach using this information: their vision was to gradually transform all roofs in The Netherlands to achieve a substantial reduction in $\mathrm{CO}_{2}$ and promote of sustainable energy and efficiency. This would require a sector-wide structural change in thinking, structure and practice.

To facilitate this sector-wide structural change ESHA's CEO, an idealistic and innovative entrepreneur, launched the Earth Recovery Open Platform (EROP) mid-2007. The platform created an open dialogue with innovative individuals representing different aspects of the field, such as construction companies, designers, urban planners, policy makers, water managers and energy companies. Within this 'transition arena', actors discuss and debate new options on how they, as a sector, could contribute to and accelerate the change towards a more sustainable society. Key actors in this process are, besides ESHA, a small number of municipalities and their local water boards (for example Leeuwarden, Groningen and Rotterdam), large manufactures of roofing products (such as Consolidated), a number of knowledge institutes (TNO, Wageningen University) and a number of companies where implementation is envisaged (for example Schiphol Airport). Environmental NGOs, social scientists and governmental organizations are involved as well. According to ESHA, this approach is necessary because such a transition needs to become the shared responsibility and ambition of the whole sector, from manufacturers to designers/ architects, builders and users. Concurrently, ESHA is investigating the opportunities for extending its own business in this emerging sustainable system. Success depends upon a multitude of innovations: new rules and regulations, new technologies, new design and manufacturing tools and practices, new financial schemes and so on. By creating a broad multi-party network and investing in a shared agenda for social change, a movement is started that in time will benefit the company.

At the tactical level, the EROP platform subsequently developed different ambitious images of roofs producing energy, buffering water, cleaning air, storing heat and cooling buildings. In the summer of 2008 , this has already led to the establishment for 'roof development companies' that exclusively scan areas of roofs that can be 'sustainably developed'. Their business is to develop roofs by creating extra value for municipalities, such as water storage, energy production or $\mathrm{CO}_{2}$ reduction. The innovative 'reframing' of roofs as functional areas that need to be developed to contribute to societal development and urban ecology is an intriguing illustration of a shift towards a more systemic mindset focused on broader sustainability issues.

Operationally, the platform is now in a process of co-developing experiments to implement these concepts. Examples are a project developing green roofs in the city of Rotterdam, a pilot at Schiphol Airport and a number of other small scale projects in Nijmegen and Groningen. Also, ESHA opened the first Ioo\% bitumen-recycling plant in 2008 and develops new $\mathrm{CO}_{2}$-extensive roofing equipment. All of these initiatives are explicitly linked to a variety of persistent societal problems in The Netherlands (such as water problems, energy dependency, poor air quality in cities, safety issues in public buildings) and geared towards fundamentally changing business as usual in their sector. By entering a cross sector process based on a shared transition, new roles and practices are being defined and experimented with, thereby trying to break away from existing routines (Baas, 2008).

${ }^{\text {I }}$ See www.esha.nl or for their transition initiative www.zwart-gras.nl (in Dutch). 


\section{Business Strategies for Transitions Towards Sustainable Systems}

At the start of ESHA's efforts, the tensions as well as the innovative potential associated with transition processes came to the fore. While in general national and local government as well as various producers supported the transition towards full use of all bitumen roofs to help solve the problem of $\mathrm{CO}_{2}$ emissions, there was fierce competition over specific technologies, options and best practices. Barriers were also encountered in the routine practices of the sector (designers and construction firms tend to rely on traditional and proven solutions), in the existing institutions and regulations (it is not yet possible to lease a roof or treat it as energy-production facility for example) and in economic structures (the social value created is not yet monetized).

Although the transition has been stimulated and structured by the EROP dialogue, it has also become clear that the two year timeframe that the CEO had set for this transition will not be enough. The transition approach employed will therefore need to invest in strategic and tactical type discussions promoting the way of thinking and insight into the complexity of the issue and to facilitate changes from within the existing regime institutions. The case has also demonstrated that resistance to systemic change can occur in terms of existing structures, culture and practices (ranging from regulation and construction codes to the practices in the manufacturing of roofs and the design of buildings).

To date, the success of their transition approach in terms of a new agenda for their sector, a set of local transition experiments, the new companies that were established and the broader public and political attention for the issue has been dependent upon the CEO and his ability to create a high quality team around him and to develop and communicate the broader narrative. Based on the ESHA team's personal motivation and ambition it became possible to invest quite substantial amounts of time and money in this process (more than a year was invested in developing the whole program), without a very clear or certain perspective on huge returns on this investment. Our findings identified a strong stated belief in the quality of their products and the opportunities for expanding their activities and profit in the long term. So far, the company has invested substantially in developing the transition agenda and network, and is only slowly starting to make money from it. They however explicitly frame it as strategic, yet uncertain, investment to create future business. In traditional terms such an approach would seem perhaps too risky for one firm, for example because of the fierce competition on minimal construction cost in this sector and the absence of mechanisms through which societal benefits of sustainable roofs can compensate the extra investments. EHSA was able to use a transition approach to roofs because it was able to simultaneously run a solid business (in other areas), thus enabling the CEO and other actors to invest time and resources in order to innovate and experiment with the green roofs.

One of the main accomplishments of the endeavor so far has been that 'roof transition' has become a shared future orientation and that the agenda has been adopted by not only the sector but also by national government. By strategically tuning into the current political debate and favorable climate for sustainability in The Netherlands, the 'roof transition' has been adopted by national policy as one of the central innovation programs for the built environment. For ESHA this has induced internal reorganization based on the developing transition strategy and the appointment of new employees with novel competences (such as chemical engineering). Concretely, they have now set up a strategy and lobby group (to exert high-level pressure), a new technology research group, an operations group (to implement and monitor projects) and a new R\&D group, all specifically linked to the transition strategy. Whether they will be able to actually overcome the regulatory, institutional and economic barriers that still exist at national, local and sector level will however depend on whether their ideas and strategy are taken up by competitors in the market and receive the necessary institutional and governmental support.

\section{Business Development for Sustainable Transportation and Energy}

Pon Holdings provides us with another example of a new business strategy for dealing with and anticipating structural changes in the business environment. Pon Holdings is a large concern with about 50 subsidiaries active in automotive and equipment and power systems. ${ }^{2}$ Recently, public attention for sustainability issues such as air quality and climate change has grown rapidly, being covered almost daily by the media. In The Netherlands, since 2004 professional attention to these issues may have increased even more because of the strategic discussions

\footnotetext{
${ }^{2}$ See www.pon.nl
} 


\section{Loorbach et al.}

and experiments organized within the energy transition process (established by the Dutch government), involving many companies, NGOs, government and knowledge institutes. The director of business development of Pon Holdings took part in several discussion groups and conferences on alternative mobility and energy solutions. ${ }^{3} \mathrm{He}$ recognized a number of societal developments and problems, such as worsening air quality, $\mathrm{CO}_{2}$ emission and climate change, which increasingly intertwine with Pon's business as basically all products include engines and fuel use. Instead of waiting to see how the market would react to the changing environment or what governmental regulations will follow, the director proposed to anticipate the market's needs by developing innovative and more sustainable products, such as vehicles on alternative fuels and alternative energy production. In 2004 the CEO agreed to install an internal sustainability platform for this.

The mission of Pon's sustainability platform is 'to work together with suppliers, partners and clients for a profitable position in the market by applying alternative fuels for sustainable energy and transportation'. The platform consists of frontrunners with innovative ideas, which can act as champions in their business units. An important goal of the platform is to create space for sustainable innovations by sharing knowledge, experience and successes among Pon's businesses. For example, one interviewee explained that the routine of selling buses with diesel engines only broke by presenting a successful sale of buses with gas engines to bus and truck salesmen: 'The people who sell buses were competing with a sort of diesel culture that exists amongst people of truck companies, transport companies and bus companies, but also amongst own colleagues, who were familiar with diesel'. Next, innovation in one business unit serves as an example for innovation in other business units. In order to increase knowledge of sustainable practices 2100 employees take part in a training program.

Pon Holdings also works with external partners to realize sustainable energy and transportation solutions. In 2007 Pon Holdings itself organized a four-day conference on sustainability to discuss sustainable transportation with clients and experts. Two years earlier, at a conference on alternative fuels one of Pon's business units, MAN Truck and Bus, consulted other companies about developing biogas as a sustainable fuel, realizing that vehicles driving on biogas would require production of biogas and conversion to natural gas quality, adjusted logistics and storage of this new fuel and adjustment of vehicle engines and fuelling methods. To establish this system innovation MAN Truck and Bus formed the Coalition for Driving on Biogas (CROB in Dutch), including MAN Rollo, DMT Milieutechniek (environmental technology), Geveke, Foundation Energy Valley and E-kwadraat consultancy. CROB aimed to offer the whole chain of a more sustainable form of transport, ultimately for equal costs as diesel, and focused first on starting up experiments for public transportation (buses). Apart from technical challenges, there were institutional and economic barriers that had to be taken to realize this system innovation.

Local governments would have to choose buses on biogas. This decision depends both on concession granting criteria and the willingness of government representatives to support innovation. Concession-granting criteria used to give priority to lowest price. As buses on biogas would be more expensive because of extra vehicle and fuel storage investments, they could only come out best if environmental benefits were given more priority. Vehicles on biogas produce little emissions and are $\mathrm{CO}_{2}$ neutral and more silent. CROB first contacted environmental departments of the provinces, which typically favor driving on biogas for its sustainability effects. However, as the real decision making power was with departments of transportation these needed to be involved as well. Next, CROB found that directly approaching a government representative could be counter-effective. For example, one representative, who was not well informed about CROB's plans before meeting them, decided that he did not want to get involved in this innovation because this would make him politically accountable for something he did not know the details of. Through trial and error, the coalition developed a step-wise process to convince government representatives. CROB asked proponents of their concept from the governmental organization (usually environmental people) to bring their colleagues from different disciplines to the table, to discuss the consequences of alternative fuels for the province in all its aspects. Concurrently they asked civil servants to inform the representative in question in time. In their presentation of the alternative fuel, CROB not only pointed to the direct environmental gains, but also showed how biogas can easily replace natural gas as the next step in the transition towards hydrogen.

${ }^{3}$ Pon is a member of the Dutch Platform Sustainable Mobility and Platform New Gas and visited several conferences on this topic, e.g. those organized by Foundation Energy Valley. 


\section{Business Strategies for Transitions Towards Sustainable Systems}

New granting criteria already made it more attractive for bus companies to invest in buses on biogas. CROB facilitated in overcoming other barriers for bus companies, such as developing the buses, production of biogas, logistics and filling stations. The production process of biogas is highly efficient. A farm with Ioo cows can produce enough energy to have 20 buses driving for one year. However, for first movers this would still imply initial extra costs. In order to cover these initial extra costs CROB successfully applied for governmental subsidies, which have become available for innovative projects contributing to the energy transition in The Netherlands. With a subsidy of 4 million Euros CROB has started projects in two different Dutch provinces to learn about possibilities and difficulties and further develop the infrastructure for biogas as a fuel. In 200926 biogas buses will drive in the province of Zeeland and 20 buses and 80 company cars in the province of Gelderland, delivering in total a reduction of 106000 tons of $\mathrm{CO}_{2}$ emissions.

\section{Discussion}

As our case examples indicate, firms can use transition thinking to develop alternative strategies for dealing with persistent sustainability problems in the energy and mobility systems. We found empirical support for 'an ambidextrous management approach that integrates foresight and broader stakeholder collaboration' (Könnölla and Unruh, 2008, p. 525). The firms in our case examples successfully experimented with multiple new approaches to sustainability in a 'shadow track' while simultaneously maintaining existing business models.

ESHA started with the recognition of a number of persistent problems such as poor air quality and water problems and strategically developed a broad discussion and action plan on innovating roofs. The departure point for Pon Holdings and CROB was the recognition of climate change, air quality problems and dependency on fossil fuels, leading them to develop alternative fuel and energy solutions on a coalition basis and in an internal innovation platform. At the same time, each company continued its regular business. Thus, their transition strategies were conceived of as innovative experiments, which ran parallel to their regular and ongoing business. By creating space (financially, institutionally and mentally) for fundamental reflection, debate and innovation, the necessary time for developing innovations is secured while at the same time matured ideas can be transferred to or even transform the core business.

To deploy such a strategy, an organization needs to develop the capacity to have concurrent flexibility (experimentation) and stability (Boons and Roome, 2005). Our examples show that firms are able to search for discontinuous innovations (e.g. driving on biogas) while exploiting existing production systems (e.g. selling diesel buses) in an ambidextrous organization (Könnölla and Unruh, 2008). External cooperation and discussion seems to increase an organization's sensitivity for environmental developments. Higher environmental awareness is likely to foster co-evolution between sustainable innovations and creating sustainable societal systems. Our cases suggest that a changing political and societal environment in terms of attention for sustainability issues poses challenges for firms, but also creates opportunities for new strategies. Embeddedness in this changing context, particularly in cultural, structural, and political terms, was a critical success factor (Baas, 2008). By identifying sustainability issues at societal level that relate to the firm, firms are able to redefine their own products and services and restructure their own practices and organization. This way they might be able to break away from the technological (Könnölla and Unruh, 2008) and paradigmatic lock-in and start to move towards new business models.

Both cases also illustrate that a transition management approach is not easy to implement and has the best chances for survival when it is initiated as a 'shadow-track' beside regular business activities. Core conditions for this to succeed seem to be a motivated high-level manager and management support for such an experimental business development, enough funding and time for development and a gradual attunement between the shadowtrack and regular policy when ideas and innovations mature. Finally, the Dutch government's macro level support for 'transitions' (in terms of both resources and political legitimacy) was integral to firm innovation and strategic planning. The Dutch government's policy on transitions created institutional space for systemic experimentation, yet it perhaps did not yet lead to the fundamental shift in governance/policymaking at the national level itself (Hendriks, 2007; Paredis, 2007). It is perhaps not coincidental that transition management originated in The Netherlands, well known for it collaborative policy making, long-term planning and innovative environmental policies. It is however also surprising, since many facets of transition management constitute a break with 
dominant approaches: a focus on frontrunners, the objective of radical innovation and the selective participatory approach (Van Buuren and Loorbach, 2009). The emergence of transition management can in this light perhaps be seen as a break with the consensual tradition of policy making in The Netherlands, which according to some is a broader and ongoing development (Jones, 2008). On the other side, the traditional political culture and practices in national and local government seem on the outside to be very much following new trends and changing quickly, while on a closer look the changes often do not go deeper than the surface (Hendriks and Tops, 2003).

Our cases suggest that the three levels of the transition management approach help to point out the purpose of organizational activities in the larger societal systems and their relation to activities of other organizations in this system. For example, at a strategic level several innovative individuals in the energy transition set goals for creating sustainable mobility and developing green gas. Within these goals, several companies formed a coalition (CROB) to develop all necessary links for production, logistics and usage of an alternative fuel (tactical level). They initiated two experiments to learn about possibilities and challenges for using biogas in different types of transportation (operational level). CROB's ambition to develop biogas as a fuel fits within the strategic discussion on sustainable mobility. This case, along with that of ESHA, suggests that firm strategies may focus on one level but simultaneously need to relate to activities at the other levels in order to stay tuned to structural changes in their sector or industry. We discuss the implications of our findings in more detail below (see Table I).

\section{Strategic Level}

The main aim of the strategic level of transition management is to develop a sustainability vision and goals at societal system level amongst a few forerunners from different societal sectors, based on a system perspective analyses. The ESHA Group utilizes these insights by starting from the analysis of multiple sustainability issues, ranging from $\mathrm{CO}_{2}$ emission and water problems to safety issues in buildings. ESHA has involved innovative

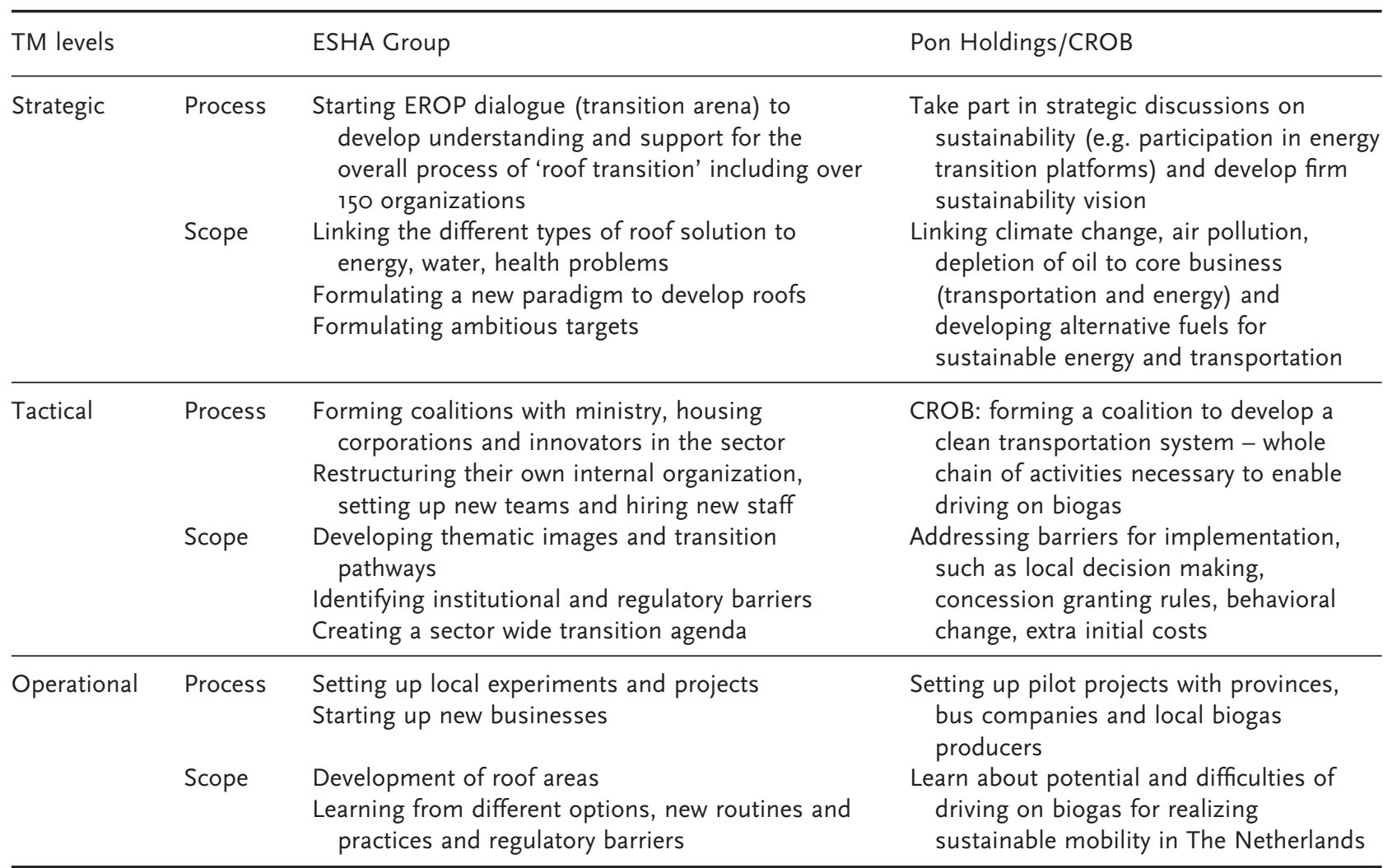

Table 1. Summary of findings 


\section{Business Strategies for Transitions Towards Sustainable Systems}

thinkers from government, competing business and NGOs (in the EROP platform) to structure the problem(s) and set long-term ambitions and goals. They are in this way creating a strategic network (arena) that internalizes the new perspective and provides support and public pressure. Creating sustainable societal (sub)systems requires collaboration with multiple parties (Gray, I989; Westley and Vredenburg, I997). Concurrently, they have identified and developed alternative applications of the core product, bituminous products, and discussed how these could conceptually contribute to dealing with the problems.

In practice, initiating such strategic discussion means that a firm needs to give space (mostly in terms of time but also in terms of competition) to innovative individuals to participate in this process and provide them with authority for articulating strategies of organizational change that can realize broader societal ambitions. Commitment to sustainability from top management and a longer time horizon support such an approach. Research shows that the individuals participating in such arenas should be 'able to redefine and reframe a complex issue and articulate abstract but coherent and believable solutions and strategies that are fundamentally different from the mainstream' (Loorbach, 2007, p. I07). Participation in some of the energy transition platforms and other conferences made Pon Holdings and other companies think about how problems of worsening air quality and climate change affect their business and could be turned into new business opportunities. Based on challenges in both energy production and transport fuels, the coalition driving on biogas used losses of current green electricity production based on heat power to produce biogas for both households and as a transportation fuel. They presented driving on biogas as the next step in the transition to driving on hydrogen. Our cases suggest that an important first step to engage in transitions is to determine to which particular societal issue(s) or transition(s) a firm can contribute. This strategic choice could be based on the characteristics of (sub)systems, that of the firm (specifically the firm's relationship to the problem) and the anticipated impact the firm has on the problem, society at large and the firm itself (Margolis and Walsh, 2003).

A central outstanding strategic issue is how firms can deal with tensions between the innovative 'shadow-track' and pressures from the existing regime; both within the firm and the sector or system it seeks to change. We found that continuously finding strategic partners, anticipating windows of opportunity and responding quickly to newly emerging developments and innovations are ways of tackling the difficulties of an ambidextrous organization (Könnölla and Unruh, 2008).

\section{Tactical Level}

At this level the firm should look for ways to further their own interests in line with societal goals formulated at the strategic level. This could imply developing strategic coalitions with other firms and organizations and collaboratively developing alternatives (pathways) to the current system, such as transportation on biogas. The partners in CROB were deliberately chosen to enable provision of all products and expertise necessary for the production, conversion and logistics of biogas as well as adjustment of vehicle engines. It also implies lobbying towards governmental organizations in terms of developing new regulation or financial instruments, conceptualized by Bendell and Kearins (2005) as managing the 'political bottom line'. In the case of CROB, the attainment of political support, change of specific rules (concession granting schemes) and governmental financial support proved critical to initiate the two first projects. In terms of management, this means the firm needs to create space for research and development, for inter-organizational collaboration and development of new business models, for instance by questioning existing routines (Baas, 2008). This could be achieved by restructuring the business organization or developing new structures to facilitate targeted activities that stimulate change and innovation in these areas, which is illustrated by the new organizational structure set up by ESHA. In the broader network around a sustainability issue, but also in specific coalitions, businesses should be aware of dependencies and power relations, as these may influence the outcomes and problem solving capacity of networks (Boons, I998).

\section{Operational Level}

Operationally, transition management aims to bring together diverse actors in concrete experiments, to learn about different aspects of an innovation - such as user preferences, regulation, ecological impact and new organizational forms. The purpose is to explore the potential contribution of an innovation (societal, technological, institutional 


\section{Loorbach et al.}

and/or behavioral) to a desired sustainable system (e.g. a clean, affordable and secure energy system). On the one hand the aim is to develop products and services that fit the strategic goals, on the other to do this in a societal (real-life) setting to explore barriers for implementation and how they can be overcome. The case of CROB, the inter-organizational coalition initiated by MAN Truck and Bus, demonstrates how resistance over driving on biogas can be overcome amongst local decision makers. Two projects are starting in 2009 both using regional produced biogas. These pilot projects give the opportunity to develop and test the local infrastructure and other necessary changes for driving on biogas. ESHA sets up local projects in collaboration with building owners, local government (water boards for example), project developers and construction industry to develop spatial plans for combinations of energy, water buffering and green roofs. Constructions based on this approach will start in 2008 , and the collaborative and experimental approach is already leading to increased enthusiasm, willingness to invest in sustainable solutions and insight in novel possibilities at a concrete level amongst the other actors. Presumably, this could in time stimulate the demand for the specific solutions.

As we have shown, the transition management approach could be used by individual firms to adjust to and anticipate structural changes in societal systems towards sustainability. Next to daily business activities, this requires a different process with a different scope. Although activities at all three levels seem necessary to eventually create structural changes in a sector or region, some firms will be better equipped to practically experiment with new innovations while others are able to think about and discuss in more abstract terms causes of persistent problems and sustainability vision. Table I gives examples of the activities at different levels found in our cases. We believe that the transition management approach offers a sensible framework for analyzing these co-evolutionary mechanisms (Porter, 2006) as it starts from a societal systems perspective, but also distinguishes different levels of action. Transition management builds on ideas around co-evolution between organizations and their environment (Porter, 2006), and the potential of innovation to benefit sustainable development. It adds however the action perspective: through systematic analysis of ongoing processes of social change as transitions, individual organizations are able to identify dynamics and strategies to deal with social change more systematically and strategically. It thereby offers chances to contribute to sustainable sectors or industries and at the same time opens up new chances for intra- and inter-firm innovation. Ultimately, as the ESHA case shows, it could function as an approach to also restructure and reorient an organization based on new business concepts.

\section{Conclusion}

Our cases support the argument that multi-stakeholder processes help to understand societal problems and its causes (Gray, I989; Svendsen and Laberge, 2005). The cases suggest, however, that different types of interrelated multi-stakeholder process are needed to create a structural change of a system. Our findings provide empirical insights into how firms engage in innovative experiments to address systemic societal problems (Porter, 2006), strategic envisioning to direct change, coalitions developing alternative pathways and dealing with resistance to change and practical experiments to learn about (im)possibilities of innovations. The type of involvement of a firm in systems change depends on both firm and individual capabilities and competences. Although the actual implementation and design of sustainable systems heavily depends on the individuals involved, the specific product and sector, and the ongoing social dynamics, we have shown that general characteristics and principles can be formulated for transition management.

Our findings support the conclusions drawn by Baas (2008) and Könnölla and Unruh (2008) that businesses need to consider themselves as coevolving actors within a wider societal system in order to achieve radical innovation leading to increased sustainability. Besides optimizing existing production systems and production lines, it can be fruitful to strategically invest in long-term innovation and also pursue exploration, or the search for discontinuous innovations and market opportunities (Könnölla and Unruh, 2008). From our cases and transition management literature, we draw the conclusion that much of the success in exploration depends on individual frontrunners, which are able to develop around them small networks (transition arenas) and gradually work towards a novel business agenda. We might conclude that this by definition depends on flexibility and personal initiative and thus cannot be institutionalized in its early phases, but our research so far is too limited to draw such conclusions decisively. 


\section{Business Strategies for Transitions Towards Sustainable Systems}

The basic notions and framework of the transition management approach seem to provide a new perspective on strategic business development in congruence with the development of sustainable systems, in which the locus of sustainability has shifted from the firm to the system (see, e.g., Baas, 2008; Korhonen and Seager, 2008). Although the transition management approach in The Netherlands has so far focused mostly on governance and policy-making strategies at a societal level, transition management has potential to support firms to adapt to and anticipate future structural changes in societal systems and influence them in more sustainable directions. Firms need to determine the sustainable development of which particular system they can contribute to and the appropriate level of their influence. In such complex multi-actor processes the transition management approach offers some basic starting points and a framework to help guide the search for new business strategies. Depending on the firm's capabilities and individual competences some should focus on contributing to or setting up strategic discussions, while others can better initiate sustainability coalitions or experiments for alternative and sustainable systems or solutions. Our cases illustrate that opportunities for new business development are within reach.

Persistent sustainability issues are too complex and interconnected to be addressed by single organizations. Thus, next to firms, government, scientific institutes, NGOs and individuals need to participate in open experimentation across a range of actors. As such, we argue for research on understanding co-evolutionary mechanisms between firms and larger systems in creating a (more) sustainable society. New paradigms based on complexity and system thinking, such as transitions and resilience, seem to provide interesting and rich frameworks to do so. As we have presented in this paper, it is practically possible to translate such understanding of transitions into concrete business action based on the transition management approach. We do however want to stress that transition management merely provides the basic approach and that implementation is very dependent on competent, creative and innovative entrepreneurs. But at least it offers a promising start to explore new business strategies for transitions to sustainable systems.

\section{Acknowledgements}

We would like to acknowledge and thank the Knowledge Network on System Innovations and Transitions (KSI) and TNO (Tom van der Horst, Emma van Sandick, Lori Tavasszy, Niels Schouten and Roland Kals) for funding and contribution to the research. We also thank Peter van Dommele (ESHA) and Cees van Leeuwen (Pon Holdings).

\section{References}

Baas L. 2008. Industrial symbiosis in the Rotterdam Harbour and Industry Complex: reflections on the interconnection of the techno-sphere with the social system. Business Strategy and the Environment I7: 330-340.

Bansal P, Gao J. 2006. Building the future by looking to the past. Examining research published on organizations and environment. Organization and Environment 19(4): 458-478.

Bendell J, Kearins K. 2005 . The political bottom line: the emerging dimension to corporate responsibility for sustainable development. Business Strategy and the Environment I4: 372-383.

Boons F. I998. Caught in the web: the dual nature of networks and its consequences. Business Strategy and the Environment 7: $204-212$.

Boons F, Roome N. 2005. Sustainable enterprise in clusters of innovation: new directions in corporate sustainability research and practice. In Corporate Environmental Strategy and Competitive Advantage, Sharma S, Aragón-Correa J (eds). Elgar: Cheltenham. 259-285.

Carroll AB. I999. Corporate social responsibility. Business and Society 38(3): 268-295.

Clarke S, Roome N. I999. Sustainable business: learning-action networks as organizational assets. Business Strategy and the Environment 8: 296-3і0.

De Haan J. 2007. Pillars of change: a theoretical framework for transition models. In ESEE 2007 Conference Integrating Natural and Social Sciences for Sustainability, Leipzig.

Ehrenfeld JR. 2005. The roots of sustainability. MIT Sloan Management Review 46(2): 23-25.

EZ, Ministry of. 2004. Innovation in Energy Policy. Ministry of Economic Affairs: The Hague.

Geels FW, Kemp R. 2000. Transities Vanuit Sociotechnisch Perspectief. MERIT: Maastricht.

Gray B. I989. Collaborating: Finding Common Ground for Multiparty Problems. Jossey-Bass: San Francisco, CA.

Hendriks C. 2007 . Making democratic sense of socio-technical transitions for sustainability. Paper presented at Politics and Governance in Sustainable Socio-Technical Transitions, Blankensee, Germany.

Hendriks F, Tops P. 2003. Local public management reforms in The Netherlands: fads, fashions and winds of change. Public Administration $8 I(2): 30 I-323$. 


\section{Loorbach et al.}

Hoffman AJ. 1997. From Heresy to Dogma. An Institutional History of Corporate Environmentalism. New Lexington Press: San Francisco.

Holling CS. 1973. "Resilience and Stability of Ecological Systems." Annual Review of Ecology and Systematics 4: I-23.

Hooghe L, Marks G. 200I. Multi-Level Governance and European Integration. Rowman and Littlefield: Oxford.

Jermier JM, Forbes LC, Benn S, Orsato RJ. 2006. The new corporate environmentalism and green politics. In The SAGE Handbook of Organization Studies, 2nd edn, Clegg SR, Hardy C, Lawrence TB, Nord WR (eds). Sage: London. 618-650.

Jones E. 2008. Economic Adjustment and Political Transformation in Small States. Oxford University Press: Oxford.

King AA, Lenox MJ. 2000. Industry self-regulation without sanctions: the chemical industry's Responsible Care Program. Academy of Management Journal 43(4): 698-7i6.

Klijn E-H, Koppenjan JFM. 2000. Politicians and interactive decision making: institutional spoilsports or playmakers. Public Administration Review $78(2): 365-387$.

Kooiman J. I993. Modern Governance: New Government-Society Interactions. Sage: London.

Könnölla T, Unruh G. 2008. Really changing the course: the limitations of environmental management systems for innovation. Business Strategy and the Environment I6: 525-537.

Korhonen J, Seager T. 2008. Beyond eco-efficiency: a resilience perspective. Business Strategy and the Environment I7: 4II-4I9.

Lewin AY, Volberda HW. I999. The coevolution of new organizational forms. Organization Science 10: 519-534.

Loorbach D. 2007. Transition Management. New Mode of Governance for Sustainable Development. Dutch Research Institute For Transitions (DRIFT), Erasmus University Rotterdam, Rotterdam.

March JG, Olson JP. 1995. Democratic Governance. Free Press: New York.

Margolis JD, Walsh JP. 2003. Misery loves companies: rethinking social initiatives by business. Administrative Science Quarterly 48(2): 268305 .

Mayntz R. I993. Governing failures and the problem of governability: some comments on a theoretical paradigm. In Modern Governance: New Government-Society Interactions, Kooiman J (ed.). Sage: London. 9-20.

Milward HB, Provan KG. 2000. How networks are governed. In Governance and Performance, Lynn H (ed.). Georgetown University Press: Washington, DC. $238-262$.

Paredis E. 2007. Translating system innovation and new forms of governance to a 'pristine' policy context. Paper presented at Politics and Governance in Sustainable Sociotechnological Transitions, Blankensee, Germany.

Porter TB. 2006. Coevolution as a research framework for organizations and the natural environment. Organization and Environment I9(4): 479-504.

Rhodes RAW. I996. The new governance: governing without government. Political Studies XLIV: 652-667.

Ring PS, Van de Ven AH. I994. Developmental processes of cooperative interorganizational relationships. Academy of Management Review I9(I): 90-II8.

Roome N. 2006. Current issues in the greening of industry. Business Strategy and the Environment I5: 137-138.

Rotmans J. 2005. Societal Innovation: Between Dream and Reality Lies Complexity, inaugural speech. Erasmus University Rotterdam.

Rotmans J, Kemp R, Van Asselt MBA, Geels FW, Verbong G, Molendijk K. 2000. Transities en Transitiemanagement: de Casus van de Emissiearme Energievoorziening. International Centre for Integrative Studies (ICIS): Maastricht.

Rotmans J, Kemp R, Van Asselt M. 200I. More evolution than revolution: Transition management in public policy. Foresight 3(I): I7.

Seager T. 2008. The sustainability spectrum and the sciences of sustainability. Business Strategy and the Environment I7: 444-453.

Shrivastava P. I995. Ecocentric management for a risk society. Academy of Management Review 20(I): II8-I37.

Stacey RD, Griffin D, Shaw P. 2000. Complexity and Management. Routledge: London.

Starik M, Marcus AA. 2000. Introduction to the special research forum on the management of organizations in the natural environment: a field emerging from multiple paths, with many challenges ahead. Academy of Management Journal 43(4): 539-546.

Starik M, Rands GP. I995. Weaving an integrated web: multilevel and multisystem perspectives of ecologically sustainable organizations. Academy of Management Review 20(4): 905-935.

Strauss A, Carbin J. I990. Basis of qualitative research: Grounded theory procedures and techniques. Sage Publications: London.

Svendsen AC, Laberge M. 2005. Convening stakeholder networks. Journal of Corporate Citizenship I9(Autumn): 9I-IO4.

Svendsen AC, Laberge M. 2006. A new direction for CSR: engaging networks for whole systems change. In The Challenge of Organizing and Implementing Corporate Social Responsibility, Jonker J, De Witte M (eds). Palgrave MacMillan: Hampshire, New York. 248-26r.

Van Buuren A, Loorbach D. 2009. Policy innovation in isolation? Conditions for policy-renewal by transition arenas and pilot projects. Public Management Review in press.

Volkshuisvesting, Rruimtelijke Ordening en Milieu, Ministerie van (VROM). 200I. Nationaal Milieubeleidsplan: een Wereld en een Wil. VROM: Den Haag.

Westley F. I995. Governing design: the management of social systems and ecosystem management. In Barriers and Bridges to the Renewal of Ecosystems and Institutions, Gunderson LH, Holling CS, Light SS (eds). Columbia University Press: New York.

Westley F, Vredenburg H. I997. Interorganizational collaboration and the preservation of global biodiversity. Organization Science 8(4): 38I403.

Wheeler D, Colbert B, Freeman RE. 2003. Focusing on value: reconciling corporate social responsibility, sustainability and a stakeholder approach in a network world. Journal of General Management 28(3): I-27.

Wheeler D, McKague K, Thomson J, Davies R, Medalye R, Prada M. 2005. Creating sustainable local enterprise networks. MIT Sloan Management Review 47(I): 33-40. 